\section{SIMPLE SCREENING FOR ABNORMAL CELLS}

Most dentists routinely screen patients for oral cancer, but how many talk to patients about what they're doing and why it's so important? The Swallows Head \& Neck Cancer Charity, set up by Chris Curtis, himself a pharyngeal cancer survivor, recently supported a Health Mela in Preston. The aim of the event was to empower communities to improve their health and well-being and Chris believes it imperative that oral health is included within any advice given about general health.

Accompanying him at that event was Nichola Jayne Tong (pictured), a hygienist who screened visitors using Goccles. Many had not even heard of oral cancer or what they could do to minimise the risk. Commenting on the day, Nichola said, 'Thankfully I did not detect any suspect lesions, but have over the years met many people who have experienced this disease. Their experiences are horrific and their faces literally bear the scars of their suffering. Sadly, oral cancer is often caught in the late stages, which is why mortality rates are higher. If caught early, the survival rate is over $85 \%$ when cancers are small.

Goccles allow clinicians to run a simple, non-invasive and painless test using the technology of fluorescence and celltissue autofluorescence by utilising the wavelengths emitted by curing-lights, a common piece of equipment in all dental practices. This adds another layer of screening to help identify potential anomalies of the oral cavity. The basic principle is that the auto-fluorescence of abnormal cells lining the mouth when exposed to light, differs to that seen occurring in normal cells. They are distributed exclusively through Dental Sky. For more information visit https:// www.dentalsky.com/goccles-oral-cancerscreening-glasses.html.

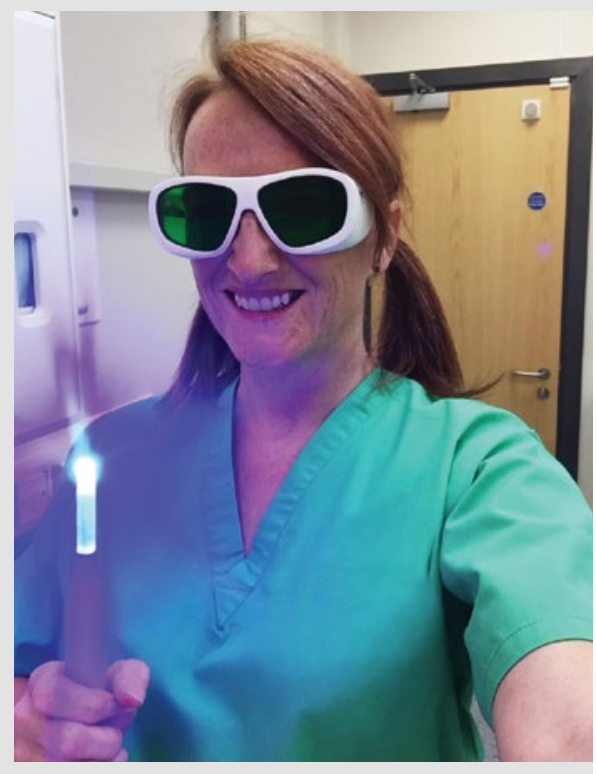

\section{BUILD A POSITIVE DENTAL EXPERIENCE FOR KIDS}

With children's oral health being such a key issue, practitioners must focus on providing a positive dental experience for their youngest patients.

Teaching children effective brushing techniques and explaining the importance of good oral hygiene not only helps to reduce their anxiety, it supports their future oral health too.

Demonstrate effective techniques with TANDEX brushes, which are high quality, functional and designed to give an efficient and gentle treatment for the smallest mouths.

TANDEX brushes and adjunctive products are for life-long oral health - click now, to find out more about the range.

For more information on Tandex's range of products, visit www.tandex.dk.

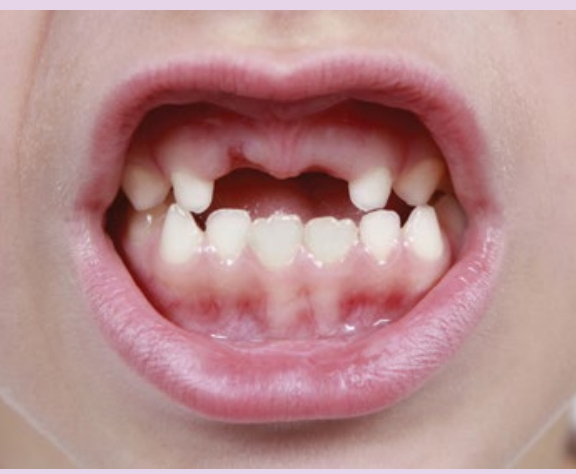

\title{
TACKLING PLASTIC POLLUTION
}

Plastic pollution has become a global crisis, but that doesn't mean it should define our future. Curaprox remains committed to minimising plastic waste, which is why it offers CPS interdental brushes that can last up to five times longer than alternative solutions.

CPS interdental brushes feature a reusable handle and replaceable brush head. Whether long or short, each handle can hold any interdental brush tip and will last for at least a year. Each tip is then inserted as required and has the potential to last for weeks, if used correctly.

Find out what other steps Curaprox is taking to tackle plastic pollution by contacting the friendly team.

For more information call 01480 862084, email info@curaprox.co.uk or visit www. curaprox.co.uk.

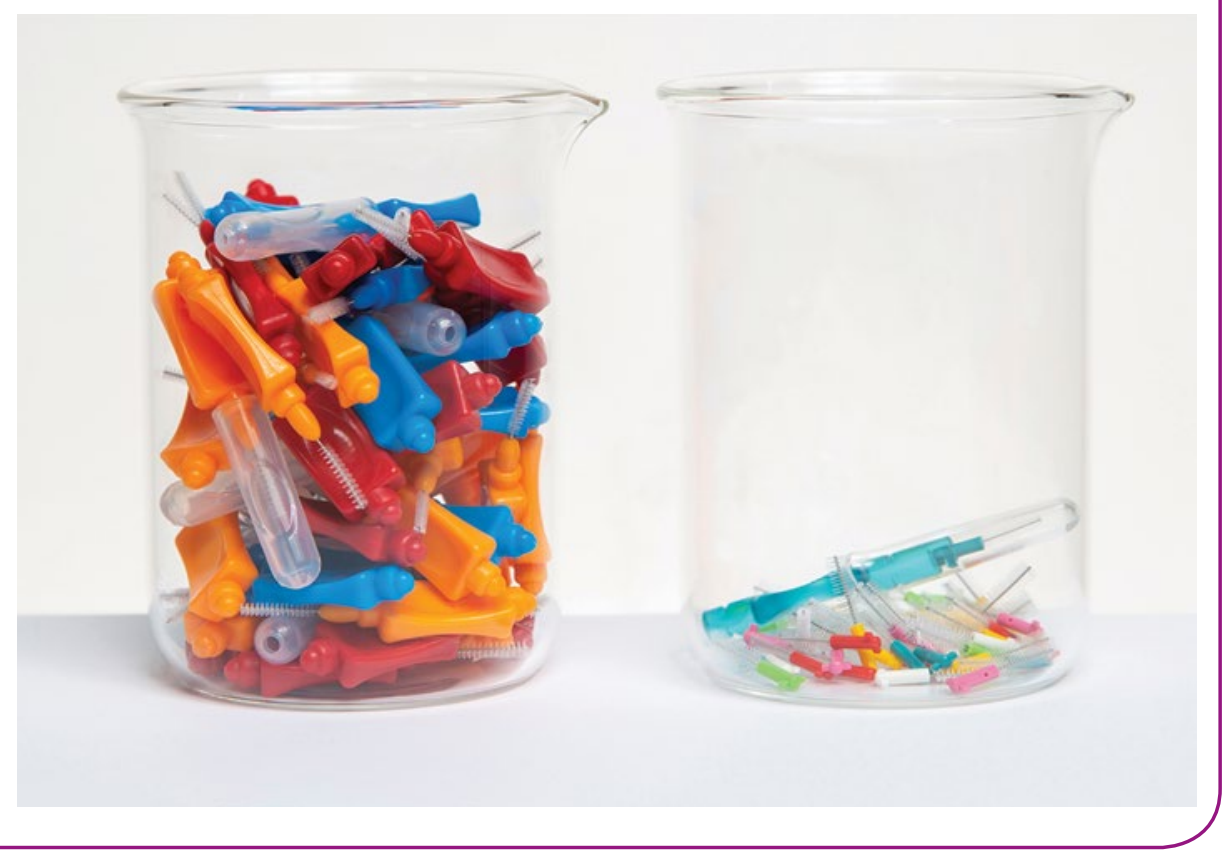

